\title{
Urbanization effect on ground beetles (Coleoptera, Carabidae)
}

\begin{abstract}
We sampled beetles in different regions of Russia (Tatarstan Republic, Mariy El Republic, Udmurtia Republic, Kemerovo, Sverdlovsk, Stavropol, Cis-Ural provinces) at sites which varied in the level of anthropogenic impact and vegetation. We used linear models to clarify how urbanization affected body size variation in studied species. All of them were palearctic generalists - Carabus granulatus, Carabus cancellatus, Pterostichus melanarius, Pterostichus niger, Poecilus cupreus, and only Carabus aeruginosus was a Siberian one. Beetles we measured for six dimensional traits. In a whole 12000 specimen have been analyzed. Results showed that different traits of Ground Beetles can response to urbanization in opposite directions: e.g. in some studies species factor "city" decreased elytra length, but increased its width and vise versa. Effect of "city" and "suburbs" factors had different directions, e. g. in a given species body size decreased in cities but in suburbs it increased and verse versa. Cognate species, which occupy similar ecological niches, have responded to urbanization in opposite directions. Females and males can respond to urbanization in opposite directions, the latter lead to the significant body size sexual dimorphism in the gradient of urbanization.
\end{abstract}

Keywords: body size variation, ground beetles, urbanization impact, linear models
Volume 4 Issue $6-2019$

\author{
Raisa A Sukhodolskaya, 'Anatoliy A Saveliev, ${ }^{2}$ \\ Natalya I Eremeeva, ${ }^{3}$ Iraida G Vorobyova ${ }^{4}$ \\ 'Institute of Problems in Ecology and Mineral Wealth, Tatarstan \\ Academy of Sciences, Russian Federation \\ ${ }^{2}$ Department of Ecological Systems Modeling, Kazan (Volga \\ Region) Federal University, Russian Federation \\ ${ }^{3}$ Institute of biology, Ecology and natural resources, Kemerovo \\ State University, Russian Federation \\ ${ }^{4}$ Department of Biology, Mari State University, Russian \\ Federation
}

Correspondence: Raisa A Sukhodolskaya, PhD, Senior Researcher, Institute of Problems in Ecology and Mineral Wealth, Tatarstan Academy of Sciences, 420087, Daurskaya str. 28, Kazan-87, Kazan, Russian Federation, Tel +7-9503I526I9, Emailsukhodolskayarais@gmail.com

Received: October 23, 2019 | Published: November 08, 2019

\section{Introduction}

Body size is the crucial trait that affects many parameters of fitness. ${ }^{1-5}$ Ground Beetles are well known bioindicators, but they are used as a rule on community level (IBM etc.). ${ }^{6,7}$ Intra-specific studies in carabids body size variation are very scarce. Usually correct statistical analysis in those researches was very weak - the single city was studied or the single trait was investigated. So there was no opportunity to conclude, if there urbanization precisely affected beetles size. Sexual structure was not taken into account too, though sexual size dimorphism is essential issue now days. ${ }^{8}$

Following certain researchers, we consider urbanization in a broader biogeographic context, exploring the impact of urbanization against different background climates. The aim of our study was meta-analysis of the effects of urbanization on carabids size variation.

\section{Material and methods}

We especially took into the analysis widespread in Paleartic generalists species - Carabus (Carabus) granulatus Linnaeus 1758, Carabus (Tachypus) cancellatus Illiger 1798, Pterostichus melanarius Illiger 1798, Pterostichus niger Schaller 1783, Poecilus cupreus Linnaeus 1758 and one Siberian species - Carabus aeruginosus F.-V., 1822. We sampled beetles in different regions of Russia in various habitats - natural, urban (cities and suburbs), rural. In the whole we inspected six cities and adjoined territories and sampled 12000 specimens.
Six traits were measured - elytra length and width, pronotum length and width, head length and distance between eyes. We used linear models to reveal, what factor (namely, region or anthropogenic) contributed into the body size variation in studied species. Then we extracted the only data concerning the impact of urbanization on body size variation in studied species and conducted Principal Components Analysis to study effect of urbanization to beetles shape variation.

\section{Results}

Response off different carabid species to urbanization varied (Figure 1). In C. granulatus beetles grew in size in urban and suburban areas, iinwe revealed the opposite effect in urban are and no effect - in suburban. Reaction in C. aeruginosus was sex-biased: males became larger in urban territories, but females in those conditions smaller. In suburban areas only males grew in size. In P. melanarius urban habitation lead to beetles decrease, but suburban had that effect only in females. In related species $-P$. niger - urban and suburban conditions did not affect beetles size. In Poec. cupreus Intercept was presented by urban habitats, then urban habitation in that species lead to decrease in size in females.

Then we PCA performed to reveal, how urbanization affected all beetles traits, i. e. Shape variation was estimated (Figure 2). In half of species studied (C. granulatus, P. melanarius, Poec. cupreus) shape variation distinctly differed in all areas studied, but in C. cancellatus, $C$. aeruginosus and $P$. niger there was no significant differences in beetles shape variation in urban and suburban areas, thought such differences occurred between urbanized and natural territories. 

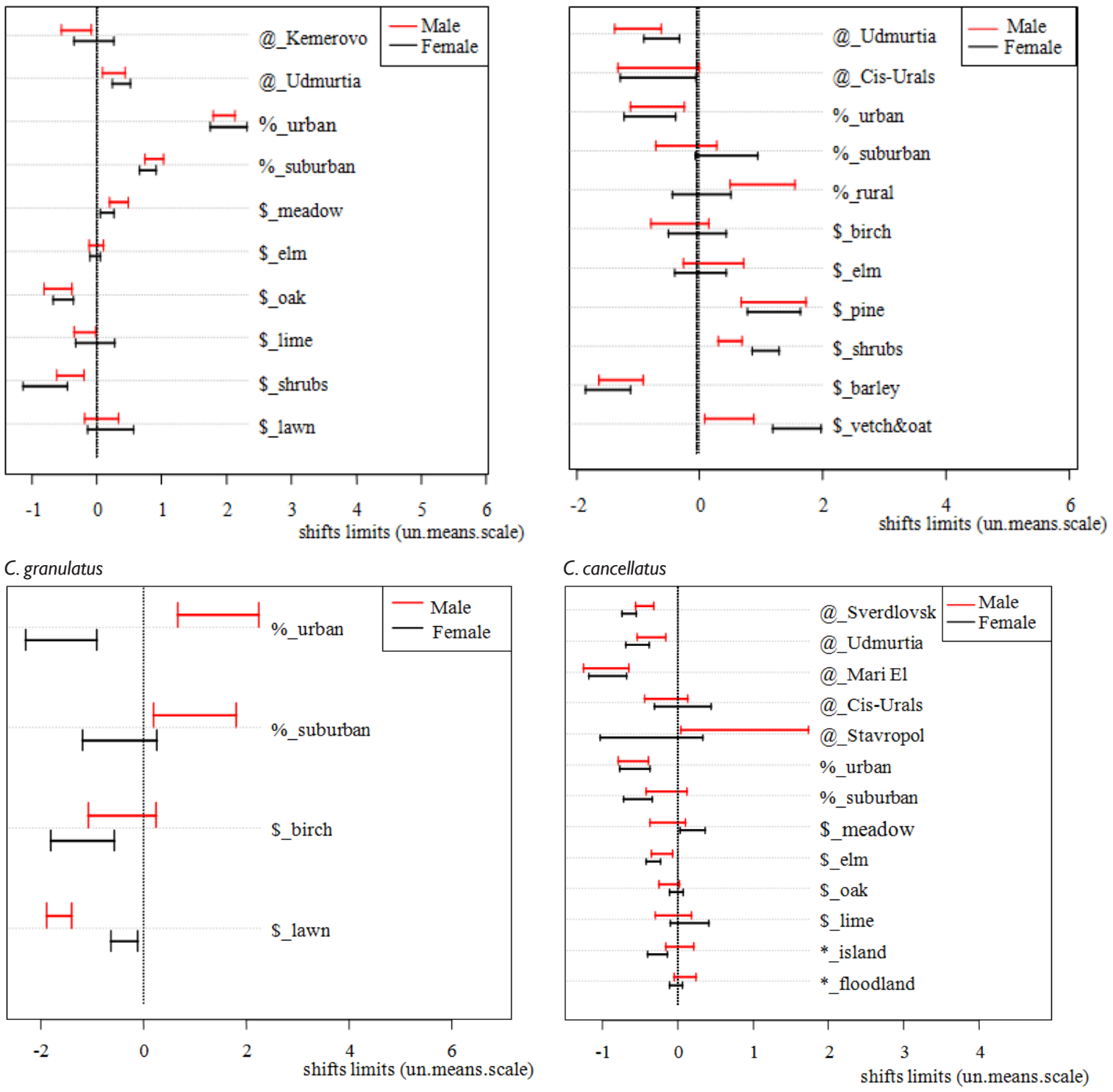

\section{C. aeruginosus}

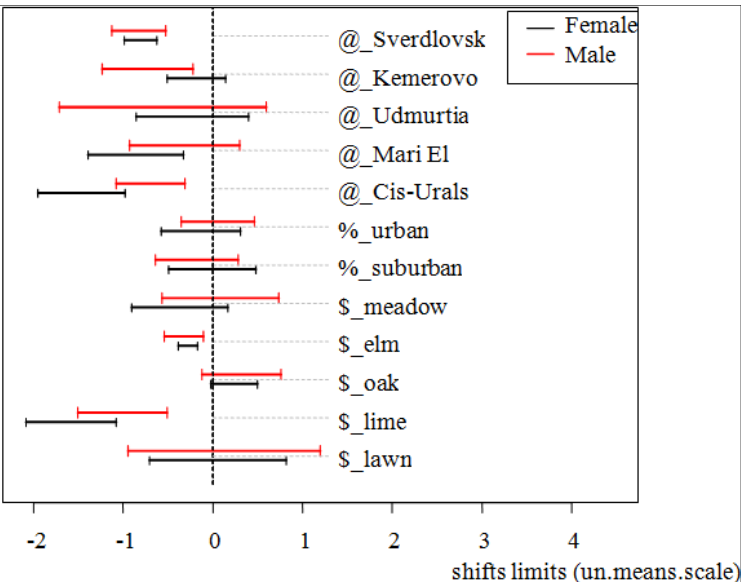

P. melanarius

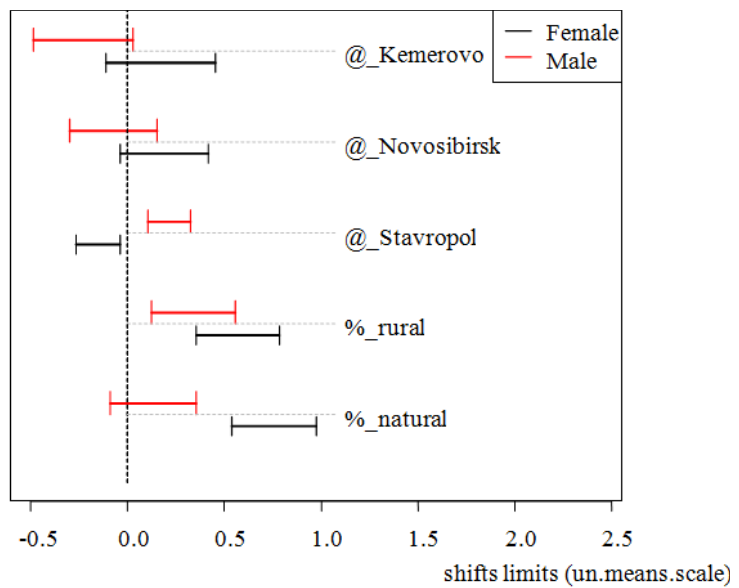

P. niger

Poec. cupreus

Figure I Shifts in elytra length in different species under the different environmental factors impact. @ - factor "Region” contribution into elytra length variation, \% - factor "Anthropogene" contribution, \$ - factor "Vegetation" contribution. Dotted vertical line denotes Intercept of the models: for region effect "Tatarstan" as the centre of area, for anthropogene effect - "natural biotope", for vegetation - the habitual vegetation for each species studied. 

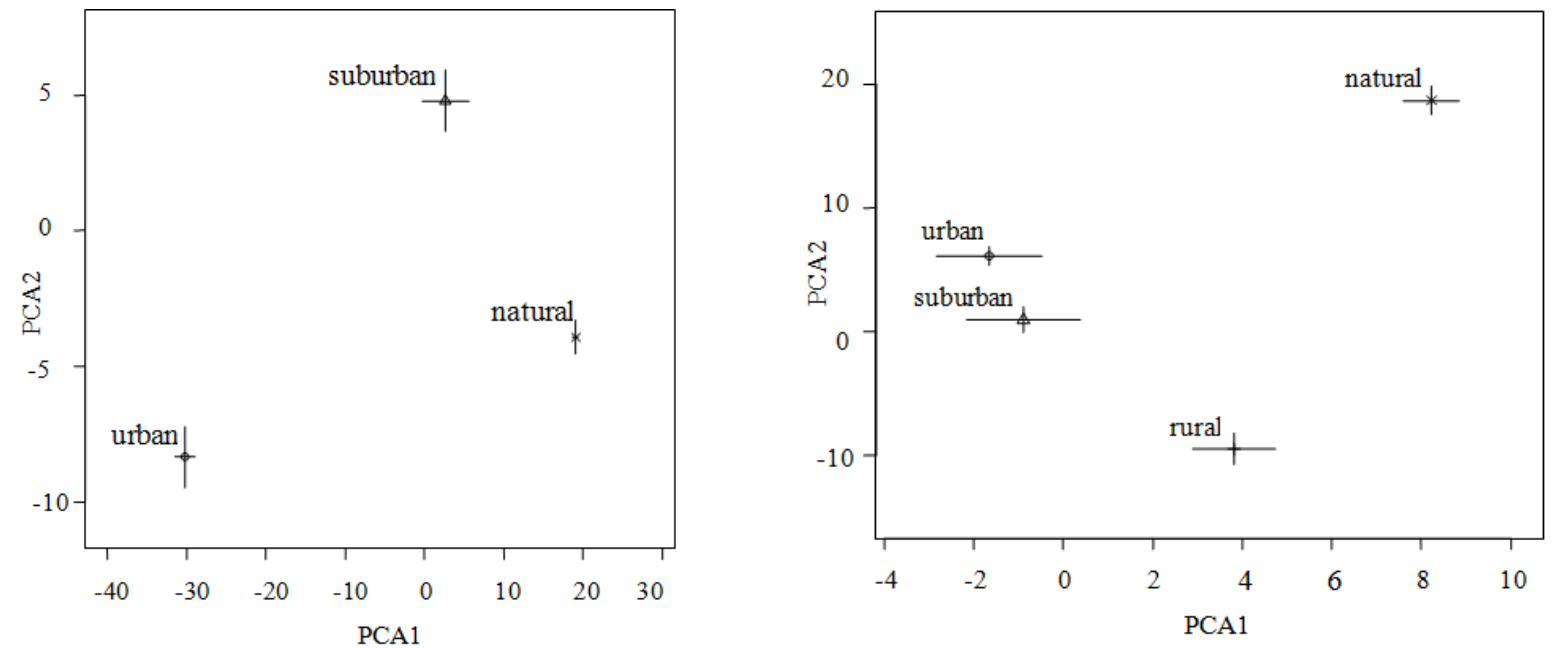

C. granulatus

C. cancellatu
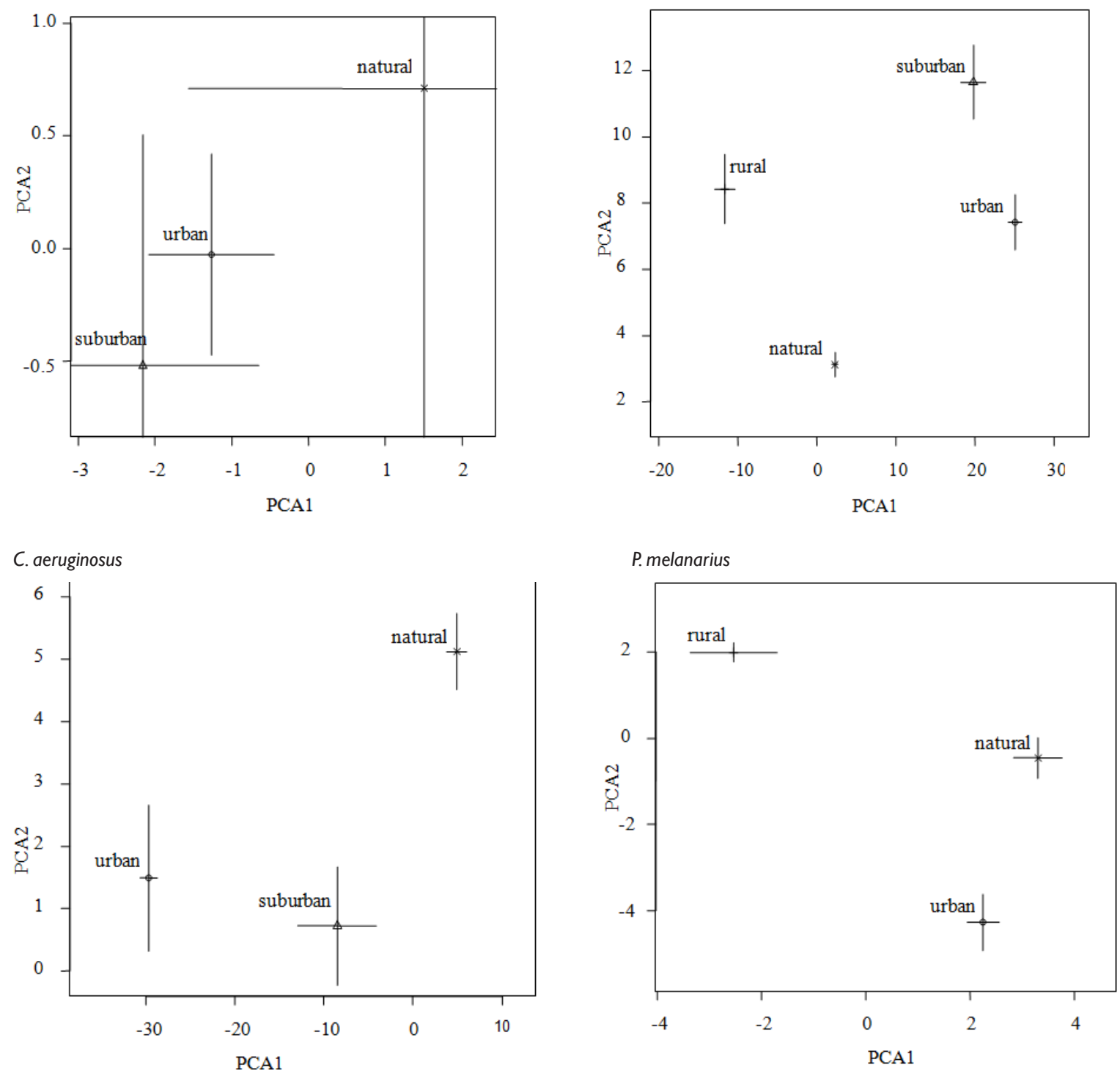

P. niger

Poec. cupreus

Figure 2 Results of PCA when analyzing urbanization impact into the beetles shape variation. 


\section{Discussion}

Significant amounts of biodiversity today are in non-protected environments under varying degrees of human manipulation. ${ }^{9}$ One of the most intensively modified human environments is urbanized areas. Urbanized areas are on the increase world-wide. By 2007, the majority of humankind was estimated to live in cities. ${ }^{10}$ Urbanization profoundly modifies the original habitat, with the loss of its plant and animal species ${ }^{11}$ their place often being taken by non-natives. ${ }^{12}$ The urbanization process seems to go through a similar sequence of events in different parts of the world, and species tolerating or thriving under such conditions can be cosmopolitan, leading to increasing biological homogenization. ${ }^{13-16}$ Urbanization occurs at different levels, and these differ in the density of humans present, the amount of the original habitat left, and often the intensity and type of management. ${ }^{17,18}$ Urban areas, however, are not devoid of plants and animals. Such areas can provide ephemeral or more permanent habitats for species, dispersal corridors or resting places for migrating organisms. ${ }^{19}$ Further, biodiversity is linked to important environmental services in urbanized areas, including the removal of dust, the mitigation of microclimatic extremes and the modulation of humidity. ${ }^{20} \mathrm{~A}$ further significant ecological service that people derive from urban biodiversity is the psychological benefits of contact with nature) ${ }^{21-22}$ While urban ecology is quickly developing, we do not yet have a detailed understanding of the effects of urbanization on biodiversity or its functioning ${ }^{23}$ Therefore it is important to document changes in biodiversity during urbanization and identify functional traits variation in certain indicator species.

In our study we revealed that even related species responded to urbanization in different ways. Some of them increased in body, another - decreased. City and suburbs habitation varied too. Carabus species were more sensitive to city impact, but Pterostichus ones to suburbs. Besides that response was sex-biased. No less important shifts occurred in the shape variation, estimated by PCA tools. In all studied species (except $C$. aeruginosus) the beetles shape differed in the gradient of urbanization, but $C$. aeruginosus did not react to human impact. These results confirmed the need of further investigations in functional traits variation in insects inhabiting urbanized areas.

\section{Conclusion}

1. Different traits of Ground Beetles can response to urbanization in opposite directions: e.g. in some studies species factor "city" decreased elytra length, but increased its width and virse versa.

2. Effect of "city" and "suburbs" factors had different directions, e. g. in a given species body size decreased in cities but in suburbs it increased and verse versa.

3. Cognate species, which occupy similar ecological niches, have responded to urbanization in opposite directions.

4. Females and males can respond to urbanization in opposite directions, the latter lead to the significant body size sexual dimorphism in the gradient of urbanization.

\section{Acknowledgments}

None.

\section{Funding}

None.

\section{Conflicts of interest}

The authors declared that there no conflicts of interest.

\section{References}

1. Angilletta J, Dunham AE. The temperature-size rule in ectotherms: simple evolutionary explanations may not be general. Am Nat. 2003;162(3):332-342

2. Berven KA, Gill DE. Interpreting geographic variation in life-history traits. Integrative Comparative Biology. 1983;23(1):85-97.

3. Dial KP, Greene E, Irschick DJ. Allometry of behavior. Trends in Ecology and Evolution. 2008;23(7):394-401

4. Juliano SA. The effects of body size on mating and reproduction in Brachinus lateralis (Coleoptera: Carabidae). Ecological Entomology. 1985;10(3):271-280.

5. Wheeler B. The role of nourishment in oogenesis. Annu Rev Entomol. 1996;41:407-431.

6. Pizzolotto R, Mazzei A, Bonacci T, et al.. Ground beetles in Mediterranean olive agroecosystems: Their significance and functional role as bioindicators (Coleoptera, Carabidae). PLoS One. 201813(3):e0194551.

7. Gerisch M. Habitat disturbance and hydrological parameters determine the body size and reproductive strategy of alluvial ground beetles. ZooKeys. 2011;(100):353-370.

8. Sukhodolskaya RA, Saveliev AA, Muhammetnabiev TR. Sexual dimorphism of insects and conditions of its manifestation. Research Journal of Pharmaceutical, Biological and Chemical Sciences. 2016;7(2):1992-2001

9. Tscharntke T, Klein AM, Kruess A, et al. Landscape perspectives on agricultural intensification and biodiversity - ecosystem service management. Ecological Letters. 2005;8(8):857-874.

10. UNPD (UN Population Division). Population challenges and development goals. New York: UN Population Division; 2005.

11. Marzluff JM, Bowman R, Donnelly R. A historical perspective on urban bird research: trends, terms, and approaches. In: Marzluff JM, Bowman R, Donnelly RE, editors. Avian ecology in an urbanizing world. New York: Kluwer Academic.

12. La Sorte FA, Boecklen WJ. Temporal turnover of common species in avian assemblages in North America. Journal of Biogeography. 2005;32(7):1151-1160.

13. Lövei GL. Global change through invasion. Nature. 1997;388:627-628.

14. McKinney ML, Lockwood JL. Biotic homogenization: a few winners replacing many losers in the next mass extinction. Trends in Ecology and Evolution. 1999;14(11):450-453.

15. Rahel FJ. Homogenization of freshwater faunas. Annual Review of Ecology, Evolution, and Systematics. 2002;33:291-315

16. Olden JD, Poff NL. Toward a mechanistic understanding of prediction of biotic homogenization. The American Naturalist. 2003;162(4):442-460.

17. Blair RB. The effects of urban sprawl on birds at multiple levels of biological organization. Ecology and Society. 2004;9(5):2.

18. McDonald RI. Global urbanization, can ecologists identify a sustainable way forward? Frontiers in Ecology and the Environment. 2008;6(2):99104.

19. Gaston KJ,Warren PH, Thompson K, et al. Urban domestic gardens (IV): the extent of the resource and its associated features. Biodiversity and Conservation. 2005; 14:3327-3349. 
20. Bolund P, Hunhammar S. Ecosystem services in urban areas. Ecological Economics. 1999;29(2):293-301.

21. Wilson EO. Biophilia. Cambridge, MA: Harvard University Press; 1984.

22. Fuller RA, Irvine KN, Devine-Wright P, et al. Psychological benefits of green space increase with biodiversity. Biology Letters. 2007;3:390-394.
23. Vandruff LW, Leedy DL, Stearns FW. Urban wildlife and human wellbeing. In: Sukopp H, Numata M, Huber A, editors. Urban ecology as the basis for urban planning. The Hague, The Netherlands: SPB Academic Publishing; 1995:203-211. 